\title{
Stress and coping in relation to gender and domicile among college students in Kashmir
}

\author{
Imtiyaz Ahmad Dar* and Naved Iqbal \\ Department of Psychology, Jamia Millia Islamia, New Delhi, India.
}

\begin{abstract}
Due to the long standing conflict, people in Kashmir, particularly college students, are subjected to constant stress. This has deleterious effects on their well-being and education. Unlike in safe situations, students living among conflict situations may have different experiences of stress and ways of dealing with it. As per transactional theory of stress and coping, the perception and reaction to the stressors may vary considerably among people. This variance may be attributed to some factors such as gender and domicile. Research regarding the role of gender and domicile on stress and coping is inconsistent and scarce. Therefore, the purpose of the current study was to examine the impact of gender and domicile on stress and coping among a sample of 80 college students in Kashmir. A $2 * 2$ factorial design was employed for analysis. Results suggest that male participants display higher stress levels than female participants, if they belong to a rural domicile. Further, it suggests that all rural and female participants, in general, employ distancing coping strategy more frequently than their counterparts. In addition, female participants employ accepting responsibility as a coping strategy more frequently than male participants, if they belong to a rural domicile. Male participants, on the other hand, were found to employ positive reappraisal as a coping strategy more frequently than females; however, this was the case when their domicile was urban. Lastly, urban male participants were found to employ accepting responsibility and positive reappraisal as coping strategies more rigorously than rural males.
\end{abstract}

Keywords: Conflict, stress, coping, college students, gender, domicile.

\section{INTRODUCTION}

Stress is an inevitable characteristic of human existence, especially in a conflict situation. Currently, Kashmir is among the most vulnerable places for various psychological problems because of the long-standing conflict of three decades. People in Kashmir are continuously exposed to trauma-related stressors. De Jong et al. (2008) have found high levels of exposure to conflict-related violence in Kashmir, with more than $80 \%$ exposed to cross-fires and roundups, $70 \%$ to some form of mental or physical torture and as many as $44 \%$ exposed to some form of mental or physical harassment.

Since 1989, the ongoing conflict has adversely crippled the normal lives of people in Kashmir. Unnatural deaths, extra-judicial killings, curfews, kidnappings, mine blasts, bomb blasts, the implementation of severe laws like Armed Forces Special Powers Act (AFSPA), Public Safety Act (PSA), Prevention of Terrorist Activities (POTA), and the presence of a huge number of armed security personnel (around 700,000) in every sphere of Kashmir have triggered the growth of psychiatric disorders in the region, on the one hand, and human rights violations, on the other (Bhat, 2014; Paul \& Khan, 2014; Duschinski, 2009; Rather, 2013).

The conflict has affected everyone, irrespective of gender, age and class. However, the present youth, who were born and raised during the turbulent phase of violence in the Kashmir history, have become the most prominent victims (Khan et al., 2012). Dr. Mushtaq Ahmad Margoob, a renowned psychiatrist of Kashmir, has used the term 'trauma generation' to refer to those who have hardly seen a minute of complete peace or tranquility in their lives and also stated that frustration,

"Corresponding author (psyimtiyaz@gmail.com; (iD https://orcid.org/0000-0001-8780-6311) 
which is one of the psychological sources of stress, is likely to occur among this generation (as cited in Khan, 2016). In their study, Amin \& Khan (2009) have reported that, in Kashmir the most vulnerable group to various psychological problems is between 15 and 25 years of age. Very high rates of mental distress and related symptoms of anxiety and depression have been reported among children and adolescents of the Kashmir Valley (Bhat, 2014; Paul \& Khan, 2014).

Therefore, youth, particularly college students, in Kashmir are continuously exposed to stressors related to ongoing conflict, on the one hand, and the educational demands, on the other. These students must respond to it daily to stay healthy. Chronic or unresolved stress can cause much physiological and psychological distress in different ways (Hudd et al., 2000). The topic of stress among college students has also captured the interest of many researchers and teachers for many years because it affects the physiological and psychological health of the students as well as their academic performance (Struthers et al., 2000).

According to the transactional theory of stress and coping, as proposed by Lazarus \& Folkman (1984), stress is a product of the transactional relationship between a person and his or her environment that is appraised as potentially causing harm to one's well-being. Two critical processes are involved in mediating this personenvironment relationship: cognitive appraisal and coping.

Cognitive appraisal is an evaluative process that determines the degree to which a particular personenvironment transaction is perceived as stressful. Two forms of appraisal are involved in this process: primary appraisal and secondary appraisal. The primary appraisal involves determining whether an event is threatening, challenging or of no consequence. The secondary appraisal involves determining the resources that are available to deal with the stressor; it evaluates the benefits and consequences of a specific coping strategy.

Coping is the process through which the personenvironment relationship is managed by the individual. It involves,

"constantly changing cognitive and behavioral efforts to manage specific external and internal demands that are appraised as taxing or exceeding the resources of the person" (Lazarus \& Folkman, 1984; p. 141).

Lazarus \& Folkman (1984) described two forms of coping strategies that are involved in managing stress: problem-focused coping and emotion-focused coping. Problem-focused coping is used to eliminate the sources of stress or reduce its impact through direct actions. Therefore, this form of coping is more probable when the stressor is appraised as amendable to change. Emotion-focused coping, on the other hand, is used when the stressors are appraised as not amendable to change, and therefore, it involves changing the emotional reaction to the stressor.

Emotion-focused coping is often cited as a maladaptive coping strategy, and this is due in part to the research associating emotion-focused coping with negative outcomes (Folkman \& Moskowitz, 2004). For example, Graven et al. (2014) conducted a systematic review of the association between coping and healthrelated outcomes among cardiac patients. Problemfocused coping was generally associated with improved self-care, psychological well-being and health-related quality of life, while emotion-focused coping was associated with poorer health-related quality of life and psychological well-being and a higher risk of mortality. Lazarus \& Folkman (1984), however, suggested that neither of these coping strategies is inherently adaptive or maladaptive. Instead, the effectiveness of a particular coping strategy is dependent on how well it corresponds with appraisals and situational conditions (Dewe \& Cooper, 2007; Folkman \& Moskowitz, 2004). Therefore, the crucial components in determining coping effectiveness are fit and context. While explaining a 'good fit' between an appraisal and coping, Zakowski et al. (2001) suggest the predominant use of emotion-focused coping when dealing with an uncontrollable stressor and the predominant use of problem-focused coping for a controllable stressor.

Emotion-focused coping is generally described to provide short-term adaptive effects, when stressors are appraised as being uncontrollable and when the existing resources are not sufficient to support problem-focused coping strategies (Ben-Zur, 2009; Terry, 1994). According to Folkman \& Moskowitz (2004), during intensely emotional environments, the initial function of coping "is to down-regulate negative emotions that are stressful in and of themselves and maybe interfering with instrumental forms of coping" (p. 747). Thus, emotion-focused coping strategies may initially be adaptive as they encourage individuals to avoid intensely emotional reactions, but the sole and persistent reliance on these strategies over prolonged periods is maladaptive (Ben-Zur, 2009; Semmer, 2006).

Based on the above discussed theoretical model of Lazarus \& Folkman (1984), the continuous nature of the stressors in the environment can have strong and lasting effects on the student's socio-emotional wellbeing if 
appraised as taxing and exceeding one's coping resources. However, the perception and reactions to the stressors may vary considerably as per some personal characteristics such as gender (Gadzella et al., 2008; Matud, 2004).

There are contradictory findings regarding gender differences in stress. Some research has reported no gender differences in stress levels (e.g., Amr et al., 2008; Yasien \& Alvi, 2018), while others have reported higher stress levels among females than males (e.g., Brougham et al., 2009; Majied \& Khan, 2015). Some others have reported higher stress levels among males than females (e.g., Chen et al., 2009; Kachroo, 2014). These conflicting findings prompt further investigation of this phenomenon.

Research regarding gender differences in stress across domicile is scarce. However, the available research suggests that rural individuals are more vulnerable to psychological disorders than urban individuals and rural females are more vulnerable than rural males (Amin \& Khan, 2009). Contrary to this, Kachroo (2014) reported higher stress levels among males when their domicile was rural. Further research is needed to explore gender differences in stress levels across domicile.

Exposure to ongoing conflict not only increases psychological symptoms but also makes the psychological coping modes ineffective in alleviating this relationship (Punamiki \& Suleiman 1990). The inability to cope with an excessive amount of stress can have a devastating effect on a student's physical and mental health (Mahmoud et al., 2012). Jong et al. (2008) stated that people in Kashmir deal with stress by isolating themselves $(22.3 \%)$ or becoming aggressive (16\%).

Previous research has also yielded mixed findings regarding gender differences in coping with stress. Some studies suggest that males make greater use of problemfocused coping than emotion-focused coping (e.g., Eaton \& Bradley, 2008; Endler \& Parker, 1990). Other studies suggest that females are more likely than males to engage in emotion-focused coping (e.g., Brougham et al., 2009; Eaton \& Bradley, 2008). However, many other studies have found no differences based on gender (e.g., Conway \& Terry, 1992; Zakowski et al., 2001). These inconsistent differences prompt for further research in this area. To address these inconsistencies, the effect of variables such as domicile may be particularly fruitful. However, there is a paucity of research concerning gender differences across domicile.

The current study was planned owing to the inconsistent gender differences related to stress and coping and also due to paucity of research concerning the impact of domicile on stress and coping among college students in Kashmir. Therefore, the study aimed to examine stress and coping among college students in Kashmir and to determine whether participants' gender and domicile affect their stress levels and coping strategies.

\section{Hypotheses}

$\mathrm{H}_{1}$ : There will be a significant effect of gender and domicile on students' stress levels.

$\mathrm{H}_{2}$ : There will be a significant effect of gender and domicile on students' coping strategies employed.

\section{METHODOLOGY}

\section{Sample}

The sample consisted of 80 college students; 40 males (20 rural and 20 urban) and 40 females (20 rural and 20 urban). Only college students between 18 and 25 years of age were selected. Participants suffering from any kind of disability or life-threatening illness were excluded from the current study. Besides, only the students who gave their consent for participation were included. The mean age of the participants was 20.48 years $(\mathrm{SD}=2.18)$. Participants were largely identified as Muslims (97.13\%) and unmarried (92.41\%).

\section{Design}

For the present study, a $2 * 2$ factorial design was used. Domicile and gender of participants acted as independent variables. Each variable had two levels viz. domicile into rural and urban, and gender into males and females. Scores on stress and eight coping strategies were dependent variables.

\section{Procedure}

Participants were recruited from different colleges of districts Baramulla and Srinagar after taking permission from respective authorities. These include 'Degree College Boys Baramulla', 'Womens' College Baramulla', 'Degree College Pattan', 'Womens' Degree College Srinagar' and 'Degree College Bemina'. The researchers individually contacted the college students and briefly introduced the purpose of the research. Consent was taken from students who were willing to participate. Students were allowed to withdraw their participation at any time. Two sets of questionnaires were given to them and they were asked to read the instructions carefully written at the beginning of each questionnaire before answering the questions.

\section{Measures}

Hari's Stress Inventory (Chandran, 2005) is a tool used worldwide to measure the amount of stress experienced in daily life. It is a 66 item scale with 
five alternatives, ranging from 'fully agree' to 'fully disagree'. Internal consistency was found to be 0.74 and the test-retest coefficient of correlation was found to be 0.79 . Cronbach's alpha in this study was 0.77 .

The Ways of the Coping Questionnaire (revised), developed by Folkman \& Lazarus (1985), measures a wide range of thoughts and acts that people use to deal with the internal and/or external demands of specific stressful encounters. It is a 66 item Likert scale with four alternatives ranging from $0=$ does not apply and/ or not used, to $3=$ used a great deal. The scale has eight coping strategies with internal consistencies reported as Confrontive coping (alpha $=0.70$ ); Distancing (alpha $=0.61)$; Self-controlling $($ alpha $=0.70)$; Seeking social support (alpha $=0.76)$; Accepting responsibility (alpha $=$ $0.66)$; Escape-avoidance (alpha $=0.72$ ); Planful problemsolving (alpha $=0.68)$; Positive reappraisal (alpha $=0.79)$. Cronbach's alpha in this study range from 0.67 to 0.86 .

In the manual for the ways of the coping questionnaire, Folkman \& Lazarus (as cited in Özkan \& Kutlu, 2010) have suggested that coping strategies viz. Distancing, Self-controlling, Accepting responsibility, and Escape-avoidance, are predominantly emotionfocused coping. Confrontive coping and Planful problem-solving are predominantly categorised as problem-focused coping. The remaining scales (Positive reappraisal and Seeking social support) are more mixed and could be seen as either emotion-focused or problem-focused coping, depending upon the situation.

\section{Data Analysis}

SPSS 18.0 was used to analyse the data; no outliers and missing values were found. Assumption of normality was satisfied as per Kline (2005) recommendations; the values of the skewness and kurtosis lied between -1.585 to 1.318 and -1.391 to 4.571 , respectively. Homogeneity of variance as assessed by Levene's test of equality of error variances was also satisfied as all $p$ values were greater than 0.05. Two-way ANOVA's were conducted to determine whether the domicile and gender of the participants affect their stress levels and coping strategies. The authors used partial eta square to indicate the effect size for each analysis; the values for small, medium, and large effects are $0.01,0.06$ and 0.14 , respectively.

\section{RESULTS}

\section{Results of two-way ANOVA for stress}

There was a significant main effect of the gender, $\left[F(1,76)=4.21, p=0.044, \eta_{\mathrm{p}}{ }^{2}=0.052\right.$, approaching a medium effect size] (see Table 1), such that male participants have higher stress levels $(\mathrm{N}=40, \mathrm{M}=225.20$, $\mathrm{SD}=24.33)$ compared to their female counterparts $(\mathrm{N}=40$, $\mathrm{M}=215.25, \mathrm{SD}=19.32)$. The main effect of domicile was non-significant $[F(1,76)=0.01, p=0.918]$. However, there was a significant interaction between the effects of gender and domicile on participants stress levels $[F(1,76)$ $=4.00, p=0.049, \eta_{\mathrm{p}}{ }^{2}=0.050$, approaching a medium effect size] (see Table 1). Simple effects analysis showed that males have higher stress levels than females if they belong to rural domicile $\left[F(1,76)=8.21, p=0.005, \eta_{p}{ }^{2}\right.$ $=0.098$, approaching a large effect size], but no gender differences were found when their domicile changed from rural to urban $[F(1,76)=0001, p=0.971$, (see Figure 1).

\section{Results of two-way ANOVA for coping strategies}

Out of the eight coping strategies, significant main effects were found with only one strategy viz. distancing. However, significant interactional effects were found with two strategies viz. accepting responsibility and positive reappraisal. The results of the remaining five strategies (Confrontive, Self-controlling, Seeking social support, Escape avoidance and Planful problem solving) did not reach the significance level (see Table 2).

For distancing coping strategy there was a significant main effect of gender $\left[F(1,76)=7.66, p=0.007, \eta_{p}{ }^{2}\right.$ $=0.092$, approaching large effect size], indicating that female participants use distancing coping strategy more frequently $(N=40, M=10.17, S D=3.15)$ than male participants $(N=40, M=8.35, S D=2.85)$ (see Figure 2). Further, there was a main effect of domicile, $\left[F(1,76)=5.00, p=0.028, \eta_{\mathrm{p}}{ }^{2}=0.062\right.$, medium effect size], such that rural participants employed distancing coping strategy more rigorously, $(N=40$, $M=10.00, S D=2.99)$ than urban participants, $(N$ $=40, M=8.52, S D=3.12$ ) (see Figure 2). However, the interaction between gender and domicile was not significant $[F(1,76)=0.01, p=0.970]$ (see Table 2).

There was a significant interaction between gender and domicile on Accepting responsibility coping strategy $\left[F(1,76)=4.44, p=0.038, \eta_{\mathrm{p}}{ }^{2}=0.055\right.$, medium effect size] (see Table 2). Simple effects analysis showed that female participants, use Accepting responsibility coping strategy more frequently than male participants, if they belong to rural domicile $\left[F(1,76)=4.763, p=0.032, \eta_{\mathrm{p}}{ }^{2}=\right.$ 0.059 , medium effect size]. However, when their domicile changes from rural to urban, no gender differences were found, $[F(1,76)=0.640, p=0.426]$. Further, it showed that urban males use Accepting responsibility coping strategy more rigorously than rural males $[F(1,76)=$ $4.45, p=0.038, \eta_{\mathrm{p}}{ }^{2}=0.055$, medium effect size]. For visual depiction of the interactional effect see Figure 3. 
Table 1: Summary of ANOVA for stress

\begin{tabular}{lrrrr}
\hline Source of variation & df & Mean square & F & Effect size \\
\hline Domicile & 1 & 5.00 & 0.01 & 0.000 \\
Gender & 1 & 189.05 & $4.21^{*}$ & 0.052 \\
Domicile *Gender & 1 & 1881.80 & $4.00^{*}$ & 0.050 \\
Within & 76 & 470.25 & & \\
\hline
\end{tabular}

${ }^{*} \mathrm{p}<0.05,{ }^{* *} \mathrm{p}<0.01$

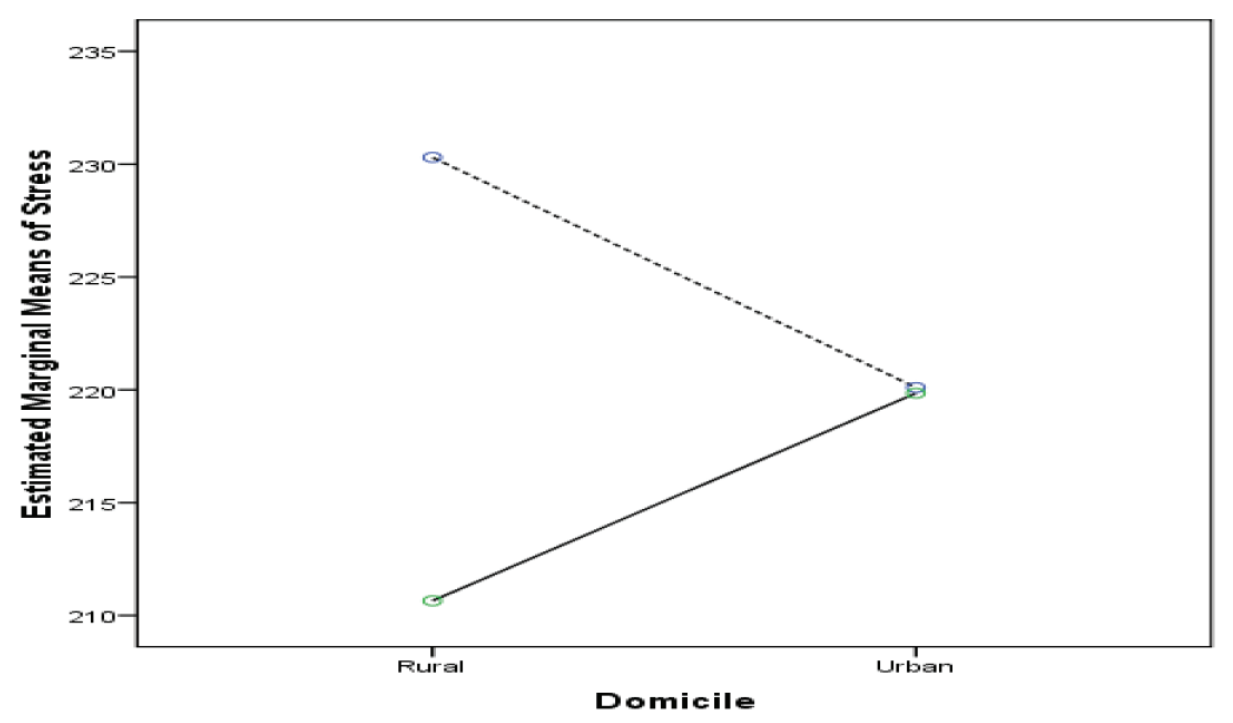

Figure 1: Interactional effect of gender and domicile for stress
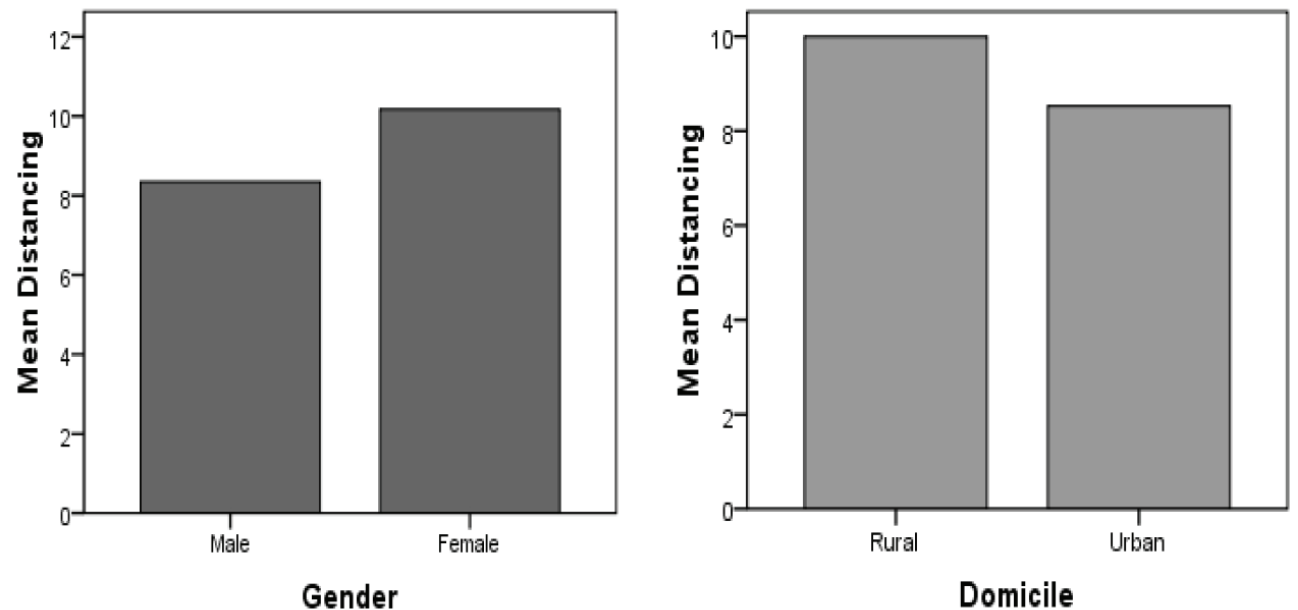

Figure 2: Mean differences for gender and domicile on scores of distancing 
Table 2: Summary of ANOVA for coping

\begin{tabular}{|c|c|c|c|c|c|}
\hline & Source of variation & $d f$ & Mean square & $F$ & Effect size \\
\hline \multirow[t]{4}{*}{ Confrontive } & Domicile & 1 & 16.20 & 1.54 & 0.020 \\
\hline & Gender & 1 & 0.05 & 0.01 & 0.000 \\
\hline & Domicile *Gender & 1 & 20.00 & 1.91 & 0.024 \\
\hline & Within & 76 & 10.51 & & \\
\hline \multirow[t]{4}{*}{ Distancing } & Domicile & 1 & 43.51 & $5.00^{*}$ & 0.062 \\
\hline & Gender & 1 & 66.61 & 7.65 & 0.092 \\
\hline & Domicile *Gender & 1 & 0.01 & 0.01 & 0.000 \\
\hline & Within & 76 & 8.70 & & \\
\hline \multirow[t]{4}{*}{ Self-controlling } & Domicile & 1 & 7.81 & 0.89 & 0.012 \\
\hline & Gender & 1 & 15.31 & 1.75 & 0.023 \\
\hline & Domicile *Gender & 1 & 27.61 & 3.16 & 0.040 \\
\hline & Within & 76 & 8.75 & & \\
\hline \multirow[t]{4}{*}{ Seeking social-support } & Domicile & 1 & 9.80 & 0.97 & 0.013 \\
\hline & Gender & 1 & 26.45 & 2.61 & 0.033 \\
\hline & Domicile *Gender & 1 & 31.25 & 3.09 & 0.039 \\
\hline & Within & 76 & 10.13 & & \\
\hline \multirow[t]{4}{*}{ Accepting-responsibility } & Domicile & 1 & 3.61 & 0.76 & 0.010 \\
\hline & Gender & 1 & 4.51 & 0.95 & 0.012 \\
\hline & Domicile *Gender & 1 & 21.01 & $4.45^{*}$ & 0.055 \\
\hline & Within & 76 & 4.72 & & \\
\hline \multirow[t]{4}{*}{ Escape-avoidance } & Domicile & 1 & 9.80 & 0.66 & 0.009 \\
\hline & Gender & 1 & 2.45 & 0.16 & 0.002 \\
\hline & Domicile *Gender & 1 & 11.25 & 0.76 & 0.010 \\
\hline & Within & 76 & 14.89 & & \\
\hline \multirow[t]{4}{*}{ Planful problem-solving } & Domicile & 1 & 40.61 & 3.14 & 0.040 \\
\hline & Gender & 1 & 5.51 & 0.43 & 0.006 \\
\hline & Domicile *Gender & 1 & 0.61 & 0.05 & 0.001 \\
\hline & Within & 76 & 12.92 & & \\
\hline \multirow[t]{4}{*}{ Positive reappraisal } & Domicile & 1 & 7.20 & 0.52 & 0.007 \\
\hline & Gender & 1 & 0.80 & 0.06 & 0.001 \\
\hline & Domicile *Gender & 1 & 110.45 & $7.98^{* *}$ & 0.095 \\
\hline & Within & 76 & 13.85 & & \\
\hline
\end{tabular}

${ }^{*} \mathrm{p}<0.05,{ }^{* *} \mathrm{p}<0.01$ 
The interaction effect of gender and domicile on Positive reappraisal coping strategy was significant, $\left[F(1,76)=7.98, p=0.006, \eta_{\mathrm{p}}{ }^{2}=0.095\right.$, approaching a large effect size] (see Table 2). Simple effects analysis showed that males use Positive reappraisal coping strategy more frequently than females when the domicile was urban $\left[F(1,96)=4.69, p=0.033, \eta_{\mathrm{p}}^{2}=0.058\right.$, medium effect size]. However, when their domicile changes from urban to rural, no gender differences were found $[F(1,96)=3.34, p=0.072]$. Further, it showed that Positive reappraisal coping strategy was used more rigorously by urban males than rural males $\left[F(1,96)=6.28, p=0.014, \eta_{\mathrm{p}}^{2}=0.076\right.$, medium effect size]. For visual representation see Figure 4.

\section{DISCUSSION}

The current study aimed to investigate whether participants' gender and domicile affect their stress levels and coping strategies. The first hypothesis which stated that there will be a significant effect of gender and domicile on students' stress levels was confirmed. Although the main effect of domicile was non-significant, the main effect of gender was statistically significant. Results provide support to previous assumptions (Chen et al., 2009; Kachroo, 2014), suggesting that males have higher stress levels than females. However, there was an interaction effect which suggests that males have higher stress levels than females, only if they belong
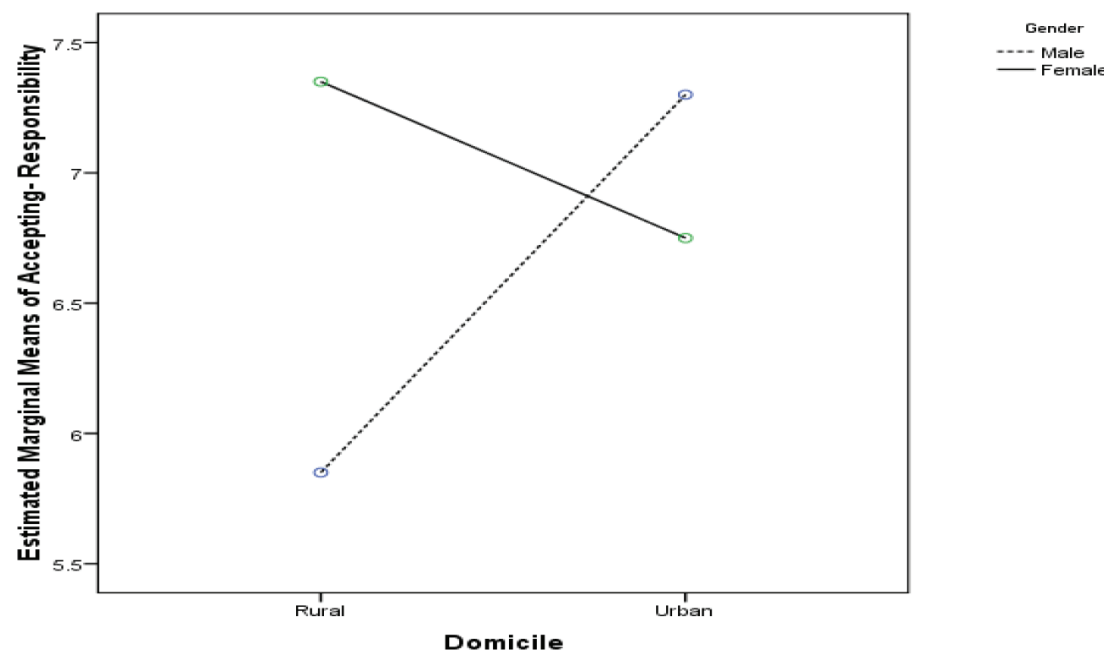

Figure 3: Interactional effects of gender and domicile for Accepting responsibility coping strategy
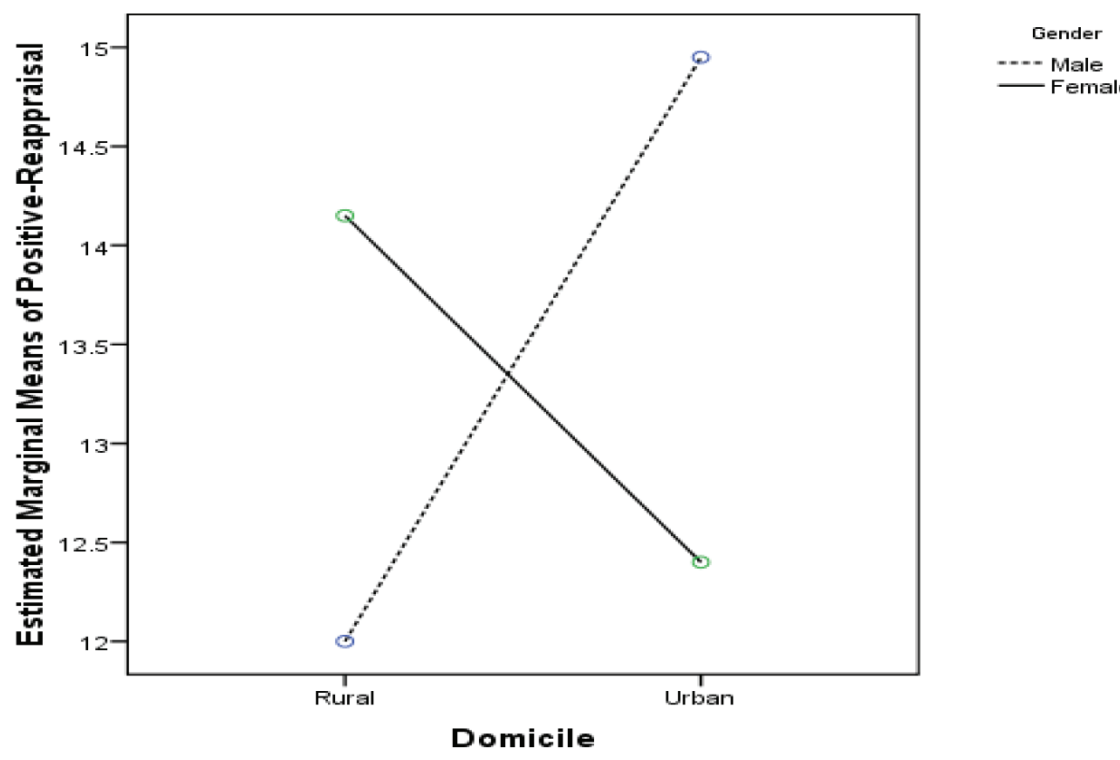

Figure 4: Interactional effects of gender and domicile for Positive reappraisal coping strategy 
to rural domicile. No gender difference was evident if they belong to urban domicile. This is consistent with the findings reported by Kachroo (2014). The possible explanation for the higher stress levels among males could be attributed to the fact that males in Kashmir are more involved in the struggle of self-determination than females, and therefore, have consistent fear and threat of being kidnapped, tortured and also due to implementation of severe laws like Armed Forces Special Powers Act (AFSPA) and Public Safety Act (PSA). According to Margoob (as cited in Khan, 2016), when exposed to the ongoing stressor daily, these youth experience frustration. Berkowitz (1993) stated that frustration creates an internal readiness to aggress, and will not follow unless and until external cues are also present. In Kashmir, since the normal expression of anger and frustration remain chocked, urban males than rural males are more frequently involved in protests and stone-pelting. The protests and stone-pelting process serve as tools of catharsis for them (Bhat et al., 2017).

The effects of stress can be altered using coping strategies. While maladaptive coping aggravates the negative effects of stress, adaptive coping acts as a buffer against stress. Research evidence suggests that problemfocused coping methods are generally more adaptive than avoidance or emotion-focused coping methods (Endler \& Parker, 1990). The emotion-focused coping strategies may also be adaptive initially, but the sole and persistent reliance on these strategies over prolonged periods is maladaptive (Ben-Zur, 2009; Semmer, 2006).

As predicted, the results confirmed the hypothesis that there will be a significant effect of gender and domicile on student's coping strategies employed. This was the case with three coping strategies viz. Distancing, Accepting responsibility and Positive reappraisal. Since Distancing and Accepting-responsibility are emotionfocused copings and are used when nothing can be done to directly change the stressor; instead, it involves changing the emotional reaction to the stressor. Results provide support to the previous assertion (Brougham et al., 2009; Eaton \& Bradley, 2008), suggesting that female participants use Distancing coping strategy more frequently than males. Further, female participants employ Accepting responsibility coping strategy more frequently than male participants, if they belong to rural domicile.

Male participants, on the other hand, were found to employ Positive reappraisal coping strategy more frequently than females; however, this was the case when their domicile was urban. The Positive appraisal is seen as either problem-focused coping or emotionfocused coping, depending on the conditions in which it is employed. Jong et al. (2008) stated that people in Kashmir deal with stress by isolating themselves or becoming aggressive. Based on this, it can be assumed that males, than females, particularly when they belong to urban domicile, may sometimes act aggressively by engaging in stone-pelting process to overcome the stress (Bhat et al., 2017), or may sometimes isolate themselves in order to rebuild the negative experiences as a result of the ongoing conflict.

Distancing coping strategy was also found to be employed more rigorously by rural participants than urban participants. However, urban male participants were found to employ Accepting responsibility and Positive reappraisal coping strategy more rigorously than rural males. Prolonged and consistent reliance on emotion-focused copings are generally maladaptive. Previous research suggests that maladaptive coping strategies and different disorders are positively associated (Endler \& Parker, 1990; Holahan et al., 1996). It has been stated that children and adolescents with pathological behavior employ maladaptive coping strategies, which can increase their pathological behaviors in the future, resulting in a vicious cycle (Selffge-Krenke, 2000). Since the conflict in Kashmir is ongoing for the last few decades with an uncertain ending, the stressors due to it are usually uncontrollable. Therefore, students in Kashmir may have to rely on emotion-focused coping strategies consistently, which in turn, may have impeding effects on their well-being.

The remaining five coping strategies viz. Confrontive, Self-controlling, Seeking social support, Escape avoidance and Planful problem solving, did not reach the significance level. Participants may use these forms of coping equally or they may have forgotten the original coping strategies they would have employed.

The contribution of the current study to the existing literature must be considered in the light of its limitations. First, the study is cross-sectional and thus, conclusions based on a cause-effect relationship cannot be drawn. Therefore, longitudinal studies are warranted. Second, the study is based on purposive sampling and therefore, may not claim a non-biased representation. Third, the sample was relatively small and may have affected the findings. Thus, further research with larger samples will be needed to confirm these results.

Despite these limitations, the current study contributes to the literature by furthering the understanding of the impact of gender and, particularly, domicile on levels of stress and coping. The current study also emphasises the need to explore the question of why males in Kashmir are more vulnerable to stress than females, particularly, when they belong to rural domicile and what stress 
intervention programs can offer them a better foredeal. Therefore, further research is necessary to explore factors that are crucial to this difference and also focus should be directed towards examining the intervention programs that will encourage them in successfully alleviating stress during the ongoing conflict. Furthermore, it emphasises the need to establish counselling cells that will offer dynamic help to the students, because relying consistently on emotion-focused coping strategies over a prolonged period will have impeding effects on their physical and mental health, as well as on their education.

\section{REFERENCES}

Amin, S. and Khan, A. W. (2009) Life in conflict: Characteristics of depression in Kashmir, International Journal of Health Sciences, 3(2), pp: 213-223.

Amr, M., Gilany, A. H. E. and El-Hawary, A. (2008) Does gender predict medical students' stress in Mansoura, Egypt?, Medical Education Online, 13(12), pp: 1-8.

DOI: https://doi.org/10.3402/meo.v13i.4481

Ben-Zur, H. (2009) Coping styles and affect, International Journal of Stress Management, 16(2), pp: 87-101.

Berkowitz, L. (1993) Aggression: Its causes, consequences and control, New York: McGraw-Hill.

Bhat, B. (2014) Mental health, anger expression and coping among male and female Kashmiri adolescents, Ph.D. (unpublished), Jamia Millia Islamia, New Delhi, India.

Bhat, M. R., Iqbal, K. and Akhtar., S. (2017) Oppression, alienation and rise of protests: insights of stone pelting from Kashmir, International Journal of Advanced Research, 5(7), pp: 2028-2035.

DOI: https://doi.org/10.21474/ijar01/4938

Brougham, R., Zail, C., Mendoza, C. and Miller, J. (2009) Stress, Sex Differences and Coping Strategies among College Students, Current Psychology, 28, pp: 85-97.

DOI: https://doi.org/10.1007/s12144-009-9047-0

Chandran, H. S. (2005) Hari’s Stress Inventory, ezine articles.

Chen, H., Wong, Y., Ran, M. and Gilson, C. (2009) Stress among Shanghai University Students, Journal of Social Work, 9(3), pp: 323-344.

DOI: https://doi.org/10.1177/1468017309334845

Conway, V. J. and Terry, D. J. (1992) Appraised controllability as a moderator of the effectiveness of different coping strategies: A test of the goodness-of-fit hypothesis, Australian Journal of Psychology, 44(1), pp: 1-7.

DOI: https://doi.org/10.1080/00049539208260155

De Jong, K., Kam, V. D. S., Ford, N., Lokuge, K., Fromm, S., Van Galen, R., Reilley, B. and Kleber, R. (2008) Conflict in the Indian Kashmir Valley II: Psychosocial impact, Conflict Health, 2(1), 11.

DOI: https://doi.org/10.1186/1752-1505-2-11

Dewe, P. J. and Cooper, C. L. (2007) Coping research and measurement in the context of work-related stress, In Hodgkinson, G. \& Ford, J. K. (eds.) International Review of Industrial and Organizational Psychology, 22, Cambridge, MA: Wiley-Blackwell.

DOI: https://doi.org/10.1002/9780470753378.ch4

Duschinski, H. (2009) Destiny effects: Militarization, state power, and punitive containment in Kashmir Valley, Anthropological Quarterly, 82 (3), pp: 691-717.

DOI: https://doi.org/10.1353/anq.0.0072

Eaton, R. J. and Bradley, G. (2008) The role of gender and negative affectivity in stressor appraisal and coping selection, International Journal of Stress Management, 15(1), pp: 94-115. DOI: https://doi.org/10.1037/1072-5245.15.1.94

Endler, N. S. and Parker, J. D. A. (1990) Multidimensional assessment of coping: A critical evaluation, Journal of Personality and Social Psychology, 58(5), pp: 844-854.

DOI: https://doi.org/10.1037//0022-3514.58.5.844

Folkman, S. and Lazarus, R. S. (1985) If it changes it must be a process: A study of emotion and coping during three stages of a college examination, Journal of Personality and Social Psychology, 48(1), pp: 150-170.

DOI: https://doi.org/10.1037//0022-3514.48.1.150

Folkman, S. and Moskowitz, J. T. (2004) Coping: Pitfalls and promise, Annual Review of Psychology, 55, pp: 745-774.

DOI: https://doi.org/10.1146/annurev.psych.55.090902.141456

Gadzella, B., Carvalho, C. and Masten, G. (2008) Differences among Gender-Role Identity Groups on Stress, American Journal of Psychological Research, 4(1), pp: 40-52.

Graven, L. J., Grant, J. S., Vance, D. E., Pryor, E. R., Grubbs, L. and Karioth, S. (2014) Coping styles associated with heart failure outcomes: A systematic review, Journal of Nursing Education and Practice, 4(2), pp: 227-242.

DOI: https://doi.org/10.5430/jnep.v4n2p227

Holahan, C., Moos, R. and Schaefer, S. (1996) Coping, stress and resistance and growth: Conceptualizing adaptative functioning, In Zeidner, M. \& Endler, N. S. (eds.) Handbook of coping: theory, research, applications, pp: 24-45, New York: Wiley.

Hudd, S., Dumlao, J. and Erdman, S. (2000) Stress College: Effects on Health Habits, Health Status and Self-Esteem, College Student Journal, 34(2), pp: 217-227.

Jong, K. D., Ford, N., Kam, S., Lokuge, K., Fromm, S., Galen, R. V. and Kleber, R. (2008) Conflict in the Indian Kashmir 
valley I: Exposure to violence, Conflict and Health, 2(10), pp: $1-7$.

DOI: https://doi.org/10.1186/1752-1505-2-11

Kachroo, W. Q. (2014) Stress among adolescents in Jammu and Kashmir, International Journal in Management and Social Science, 2(3), pp: 47-60.

Khan W. (2016) Conflict in Kashmir: Psychosocial Consequences on Children, In: Deb, S. (ed) Child Safety, Welfare and Well-being (Chapter 7), New Delhi: Springer.

DOI: https://doi.org/10.1007/978-81-322-2425-9_7

Khan, S., Maqbool, A., Abdulla, N. and Ken, M. Q. (2012) Pattern of ocular injuries in stone palters in Kashmir valley, Saudi Journal of Ophthalmology, 26(3), pp: 327-330.

DOI: https://doi.org/10.1016/j.sjopt.2012.04.004

Kline, R. B. (2005) Principle and practice of structural equation modeling, New York: Guilford.

Lazarus, R. and Folkman, S. (1984) Stress, appraisal, and coping, New York: Springer Publishing Company.

Mahmoud, J., Staten, R., Hall, L. A. and Lennie, T. A. (2012) The relationship among young adult college students' depression, anxiety, stress, demographics, life satisfaction, and coping styles, Issues in Mental Health Nursing, 33(3), pp: 149156.

DOI: https://doi.org/10.3109/01612840.2011.632708

Majied, N. \& Khan, M. S. (2015) A study of level of stress, general health, personal values and tendency of aggressive behaviour among adolescents of Jammu \& Kashmir regions, $\mathrm{Ph}$. D., Aligarh Muslim University, Aligarh.

Matud, M. (2004) Gender Differences in Stress and Coping Styles, Personality and Individual Differences, 37, pp: 14011415 .

DOI: https://doi.org/10.1016/j.paid.2004.01.010

Özkan, S. and Kutlu, Y. (2010) Evaluation of coping strategies, social support, and depressive symptoms in spouses of patients with hematological cancer, Turkish Journal of Medical Sciences, 40(6), pp: 925-936.
Paul, M. A. and Khan, W. (2014) Prevalence of mental disorders among school children of Kashmir Valley, Ph. D., Jamia Millia Islamia, New Delhi.

Punamiki, R. L. and Suleiman, R. (1990) Predictors and effectiveness of coping with political violence among Palestinian children, British Journal of Social Psychology, 29(1), pp: 67-77.

DOI: https://doi.org/10.1111/j.2044-8309.1990.tb00887.x

Rather, A. F. (2013) Armed conflicts in J\&K and its impact on society: A case study of Kashmir Valley, International Journal of Scientific and Research Publications, 3(2), pp: 1-3.

Selffge-Krenke, I. (2000) Causal links between stressful events, coping style and adolescent symptomatology, Journal of Adolescence, 23(6), pp: 675-691.

DOI: https://doi.org/10.1006/jado.2000.0352

Semmer, N. K. (2006) Personality, stress, and coping, In Vollrath, M. E. (ed.) Handbook of Personality and Health, pp: 73-113, Chichester, UK: John Wiley \& Sons.

DOI: https://doi.org/10.1002/9780470713860.ch4

Struthers, C.W., Perry, R. P. \& Menec, V. H. (2000) An examination of the relationship among academic stress, coping, motivation, and performance in college, Research in Higher Education, 41(5), pp: 581-592.

Terry, D. J. (1994) Determinants of coping: The role of stable and situational factors, Journal of Personality and Social Psychology, 66(5), pp: 895-910.

DOI: https://doi.org/10.1037//0022-3514.66.5.895

Yasien, S. \& Alvi, T. (2018) Stress and coping strategies in undergraduate medical students, International Journal of Humanities and Social Sciences, 10(1), pp: 33-39.

Zakowski, S., Hall, M., Klein, L. and Baum, A. (2001) Appraised control, coping, and stress in a community sample: A test of the goodness-of-fit hypothesis, Annals of Behavioral Medicine, 23(3), pp: 158-165.

DOI: https://doi.org/10.1207/s15324796abm2303_3 